\title{
La Iglesia ortodoxa: su papel en la identidad de Rusia
}

DOI: $10.32870 /$ mycp.v6i20.211

José Jesús Bravo Vergara*

$\mathrm{L}$ a Iglesia ortodoxa rusa tiene una historia de más de mil años. Desde la introducción del cristianismo en 988 por el príncipe Vladimiro hasta épocas recientes, se ha constituido como uno de los pilares de identidad del pueblo ruso, y durante algún tiempo -especialmente en la ocupación tártara de doscientos años- se confirmó no sólo como uno de los pocos elementos de unificación, sino también como uno de los bastiones de la lucha por la restauración de la unidad política de Rusia.

Tras la caída de Bizancio en 1453, la interacción entre el Estado, el pueblo y la propia Iglesia ortodoxa hizo que los rusos asumieran y promovieran la idea de la sucesión rusa como sede del cristianismo, así como la autopercepción de una misión histórica de unificación de todos los pueblos eslavos.

De esta forma, la Iglesia ortodoxa rusa, cuya tradición popular sostiene que el propio San Andrés (uno de los doce apóstoles de Jesús) predicó el evangelio en las colinas de lo que hoy es la ciudad de Kiev, no sólo ha sobrevivido al yugo mongol, a la influencia de Occidente o al poder soviético, sino que ha participado activamente en la conformación de la conciencia nacional y los valores identitarios del pueblo ruso.

\section{Mitología pagana rusa}

Antes de adoptar el cristianismo, los antiguos eslavos tenían sus propios dogmas. En primera instancia, creían en la dualidad: la luz, que equivalía a la fuerza creadora, al bien, y la oscuridad, el mal que se proponía destruir todo lo conocido.

* Investigador del Departamento de Estudios Internacionales, de la Universidad de Guadalajara.
Tenían una arraigada creencia en el poder de los antepasados muertos, los que se dedicaban a proteger las casas de las familias, y de ellos dependían la salud y la fertilidad.

Entre los dioses eslavos estaban Svarog, el más antiguo y poderoso. Sus hijos, Dazhbog, dios del sol, y Svarozhich, del fuego. Rod, dios de la fertilidad, la luz y la creación, relacionado directamente con los antepasados muertos. Las Rozhanitsi, madre e hijas, diosas encargadas de la fertilidad humana y de los campos.

Svantovit era un dios de cuatro cabezas fuente de un gran poder y relacionado con el culto a los antepasados. Éste llevaba un cuerno lleno de vino, cuyo nivel predecía las cosechas. También vaticinaba los resultados de las batallas con la ayuda de un sagrado caballo blanco. Perun, dios del trueno, el rayo y la guerra. Makosh, diosa de la fertilidad, la abundancia y la humedad. Veles, dios de los muertos, protector del ganado y del comercio. Stribog, el dios de los vientos.

Estos dioses y creencias no se acabaron con el cristianismo, sino que se fueron reduciendo poco a poco a lugares más aislados, aldeas rurales y poblados olvidados en medio de amplios bosques, donde pudieron subsistir durante siglos. ${ }^{1}$

\section{O rígenes del cristianismo en Rusia}

A fines del siglo IX el príncipe Oleg de Novgorod ocupó Kiev y unificó el norte y el sur de Rusia en un solo reino. En su afán de grandeza se dirigió contra Bizancio, imperio con el que ya tenía una relación comercial importante, y le impuso tributo bajo la amenaza de una invasión. 
Tras la muerte de Oleg, le sucedieron el príncipe Igor y el célebre Sviatoslav, pero ninguno de ellos logró concretar la alianza de las tribus rusas. Tras la muerte de este último, y después de numerosas luchas intesivas, subió al poder Vladimiro, el cual se vio inmerso en un peligroso ambiente de inestabilidad entre las tribus eslavas.

No obstante los problemas internos, la Rusia de Vladimiro tenía un gran poder militar y en el año 987 el emperador bizantino Basilio II, viéndose en peligro de una guerra civil le solicitó su ayuda para vencer a Phokas Bardas (Rauschenbach, 1988: 118), el general rebelde que buscaba apoderarse del trono de Constantinopla. El monarca ruso accedió a la petición de Basilio II con la condición de que le diera la mano de su hermana, la princesa Ana.

Aunque Basilio II derrotó a Phokas Bardas con la ayuda de los rusos, no cumplió con su promesa y desató la ira de Vladimiro, quien emprendió un furioso sitio contra la ciudad de griega de Querson o Korsun, la actual Jersonés, en Crimea. La corte bizantina se vio forzada a entrar en negociaciones, resultando de ello un tratado de paz y amistad de consecuencias históricas para la iglesia ortodoxa griega y para el pueblo ruso.

Para poder casarse con la princesa Ana, Vladimiro se bautizó en el templo de Santa María de Querson, e hizo bautizar también a sus tropas. ${ }^{2}$ Posteriormente, Vladimiro regresó a su país y se convirtió en un ferviente defensor del cristianismo oriental. ${ }^{3}$

Tanto el monarca ruso como su pueblo ganaron un mayor reconocimiento de los grandes imperios de la época, porque en primera instancia Vladimiro quedaba "santificado y bendito por Dios". En segundo lugar, los comerciantes rusos podían negociar con Bizancio y otros pueblos cristianos o musulmanes, como correligionarios y no como bárbaros. Al mismo tiempo, accedían a conocimientos, doctrinas y tecnologías que Bizancio desarrollaba.

El cristianismo ortodoxo quedó aún más arraigado cuando tras la muerte de Vladimiro, se presentó la amenaza de la desarticulación de la Rus de Kiev debido a la serie de peligrosas escaramuzas por la sucesión del trono entre sus hijos, Sviatopolk, Boris y Gelk, en la que el primero mandó matar a los dos últimos sin que éstos pusieran resistencia ya que creían necesario su propio sacrificio para salvar la unidad del reino. Así, Boris y Gelk se convirtieron, junto a su padre, en los primeros santos de la Iglesia ortodoxa rusa (Russian Today, 18 de julio de 2000).

\section{Separación de la iglesia}

La separación entre latinos (católicos) y ortodoxos tuvo características que van desde lo teológico y lingüístico, hasta lo político. En el Occidente cristiano la misa se celebraba en latín, el idioma oficial del imperio y tras la caída de éste, el papado se lo había adjudicado en la expansión del adoctrinamiento de los pueblos paganos al cristianismo. ${ }^{4}$

La relevancia de las discusiones teológicas acerca de la naturaleza de la santidad en vida del propio Jesús. Estas discusiones surgieron cuando la iglesia occidental añadió la palabra latina filioque (y del hijo) al credo, para indicar que el espíritu santo procedía del padre y del hijo. La problemática de ello es que para los obispos orientales el espíritu santo no procedía del hijo, sino que lo antecedía, porque el hijo del hombre sólo se santificó una vez que resucitó y ascendió a los cielos (Franz, 1990: 280).

La cuestión política comenzó desde la propia cristianización del imperio en el año 315. Esto fue debido a que Constantino plasmó su poder en la parte oriental del imperio (de habla y filosofía griegas). Al derrumbarse la parte occidental del imperio romano en 476 , solo sobrevivió la parte oriental, la cual se transformó en Bizancio, ello sin dejar de sustentarse como la única y legítima heredera de la antigua Roma.

En el transcurso de siglos posteriores, el papado y los obispos orientales entraron en conflicto por el tema de las imágenes, las cua- 
les constituían, para aquellos de habla griega, una desviación casi igual a la idolatría; no obstante, esa problemática quedó superada. En el año 861 una nueva pugna entre el Papa Nicolás y el Patriarca de Constantinopla, Focio (causada por el reclamo de Roma de que le devolvieran la jurisdicción directa de las sedes de Italia meridional, Sicilia y Salónica) terminó con una separación total no sólo entre los dos líderes religiosos, sino también en el apoyo irrestricto del emperador Miguel III al patriarca Focio y en un ataque frontal a la autoridad pontificia.

El cisma definitivo entre ambas iglesias fue en 1054. El origen de esta nueva lucha se centró en desacuerdos teológicos sobre la naturaleza del espíritu santo y el ayuno de los sábados, pero esencialmente en la disputa sobre las esferas de influencia entre Roma y Constantinopla y la demanda de reconocimiento de poder magnánimo por parte del emperador bizantino (Maier, 1983: 222-223).

Asimismo Rusia, cuya sede metropolitana en Kiev había sido aceptada y promovida por Bizancio, siguió a Constantinopla en el cisma con Roma en 1054, cerrándose religiosamente a todo lo occidental. ${ }^{5}$

\section{Afianzamiento de la Iglesia ortodoxa en Rusia}

En 1240, cuando las tropas de Batú Khan (nieto de Gengis Khan) atacaban Kiev en el lado noroccidental, suecos, alemanes y daneses preparaban la ocupación de las tierras controladas por Novgorod. El primero en lanzarse a la aventura fue Birger Jarl, el fundador de Estocolmo, pero fue derrotado y ahuyentado por el célebre Alexander Nevsky (del Neva).

Dos años después, los caballeros teutónicos trataron de ocupar las tierras rusas bajo el auspicio de la Iglesia católica, la cual esperaba nuevos tributarios. Para darle un barniz de decencia al asunto, la agresión recibió el nombre de cruzada por el carácter ortodoxo de los rusos (Kortkov, 1984: 98-99). Sin embargo, esta invasión quedó conjurada y los caballeros teutónicos fueron aniquilados a las orillas del lago Peipus. Así, los rusos defendieron sus tierras y su independencia religiosa. Aun así, los rusos cayeron bajo las huestes mongolas de Batú Khan por más de doscientos cincuenta años, y ello representó lo que se considera el histórico atraso de Rusia. ${ }^{6}$

Durante el dominio mongol, la Iglesia ortodoxa fungió como intercesora entre los débiles y desorganizados príncipes rusos y sus opresores mongoles. También conservó lo que quedaba del legado de Kiev, convirtiéndose así en la fuerza unificadora de un enorme pueblo desunido y desmoralizado.

En 1448 el Concilio de prelados rusos elevó (en forma independiente de la de Constantinopla), la catedral metropolitana de Moscú y de todas las Rusias. Con ello, la Iglesia ortodoxa rusa consiguió la autocefalia, es decir, una completa independencia jurisdiccional que tomó un sentido plenamente nacionalista.

\section{Rusia, la heredera de Bizancio}

Con la toma de Constantinopla por los turcos musulmanes (1453) y con su templo Santa Sofía $^{7}$ convertido en una mezquita, Moscú se autoproclamó la sucesora y defensora del cristianismo ortodoxo. En el siglo XVI la Iglesia ortodoxa rusa se convirtió en la más grande y en la única de todas las iglesias ortodoxas, e independiente del poder heterodoxo, ya sea bajo imperios musulmanes o católicos, como sucedía en Europa del este y en los Balcanes. Con ello, la Iglesia ortodoxa se constituyó como un elemento identitario y nacionalista de Rusia. ${ }^{8}$

El 26 de enero de 1589 se instituyó el trono patriarcal de Moscú. Con ello, el Patriarca de Moscú quedó a la altura del propio pontífice.

En el transcurso del siglo XVII, y una vez expulsados los invasores polacos y suecos de suelo ruso, se llevó a cabo una reforma eclesiástica dirigida por el Patriarca de Moscú, Tikon, destinada a corregir los ritos, la litur- 
gia y los libros oficionarios según la ortodoxia griega. Esto provocó una escisión de la raskol de staroobriadtsi (secesión de los antiguos creyentes), los cuales no aceptaron dichas reformas, pero también el éxito entre la inmensa mayoría del pueblo.

El patriarcado se prolongó hasta comienzos del siglo XVIII cuando Pedro el Grande estableció una serie de reformas no sólo en la política y en la sociedad rusa, sino también en el propio corazón de la iglesia. En 1718, el zar impuso la gobernación colegial de la Iglesia rusa, la cual estuvo vigente hasta 1721 , año en que el Colegio Eclesiástico se transformó en el denominado Santo Sínodo gobernante, instituido como supremo órgano administrativo de la Iglesia ortodoxa rusa.

En ese período, el gobierno centró gran parte de su atención en ilustrar religiosamente a su pueblo. También fue una de las épocas más brillantes en el desarrollo de actividades misioneras que abarcaron las periferias más alejadas del imperio ruso e incluso fuera de sus fronteras.

Entre 1818 y 1820, después de haber tenido un papel fundamental en la lucha del pueblo ruso contra los franceses y sus ideales, la Iglesia ortodoxa editó la versión rusa del Nuevo Testamento, la cual complementó en 1876. Al mismo tiempo se desarrolló la fundación de crecientes sociedades de ilustración religiosa en todo el imperio.

Sin embargo, las ideas del paneslavismo y su extensión religiosa involucraron al imperio ruso en numerosas empresas bélicas destinadas a lograr la expansión no sólo de intereses territoriales, sino también de la influencia rusa dominada fuertemente por la religión y apoyada por la propia Iglesia ortodoxa. ${ }^{9}$

El imperio, con apoyo de la Iglesia, se expandió hacia el Este y ocupó Siberia y los pueblos de Asia central, lo que se desató una enorme migración rusa (de alrededor de $7 \mathrm{mi}-$ llones de personas) hacia los nuevos territo- rios incorporados entre 1846 y 1914 , y se establecieron ahí numerosos monasterios con el afán de facilitar su influencia (Palmer y Colton, 1980: 316-317).

Al mismo tiempo que la iglesia ortodoxa fue utilizada para adoctrinar a los nuevos vasallos del imperio ruso, también promovió, en detrimento del grueso de la población, la intervención militar de Rusia en los Balcanes en 1877 y posteriormente durante la primera guerra mundial.

\section{Supresión de la Iglesia ortodoxa rusa}

Durante los albores del siglo XX, las diversas intervenciones militares rusas fueron realmente desafortunadas en la mayoría de los conflictos; ello trajo la pérdida de millones de vidas y el infortunio de millones de campesinos. El costo político producido por esta situación fue la caída del zar en 1916.

Una vez derrocado Nicolás II, el Concilio general de la Iglesia ortodoxa rusa aprobó la disposición de restaurar la gobernación patriarcal en 1917, pero la toma del poder por los bolcheviques impidió que la reinstalación del patriarcado tuviera éxito.

En primera instancia, la expropiación de la tierra por el soviet en 1917 dejó a la Iglesia desposeída de la mayor parte de sus propiedades agrarias, incluidos sus monasterios. Un año después, el Consejo de Comisarios del Pueblo aprobó un nuevo decreto sobre la separación entre la Iglesia y el Estado, y entre la escuela y la Iglesia. Así, todas las organizaciones eclesiásticas quedaron privadas de sus derechos y propiedades.

Posteriormente, durante los primeros años de la era comunista, la Iglesia ortodoxa rusa sufrió las consecuencias de su influencia y de ser una indiscutiblemente célula institucional de la Rusia zarista. Miles de clérigos, obispos, monjes y demás religiosos fueron víctimas de represión y muerte por parte de los bolcheviques. 
La persecución se convirtió en tragedia de enormes proporciones cuando, entre 1921 y 1922, el gobierno soviético exigió la entrega de los abundantes tesoros acumulados por la Iglesia durante el transcurso de los siglos, con el fin de ayudar a la población hambrienta tras el fracaso de las cosechas de 1921. Los resultados fueron, por un lado, millones de muertos por la hambruna y, por otro, la supresión total de la Iglesia ortodoxa, cuya estructura quedó casi destruida.

Sin embargo, tras los años de purgas estalinistas contra la población civil en la década de los treinta, los soviéticos sufrieron una invasión alemana de magnitud indescriptible, y en su desesperación por evitar la derrota, José Stalin se vio forzado a utilizar todos los recursos nacionales posibles para la defensa. Así, la Iglesia ortodoxa fue de nueva cuenta utilizada como una fuerza en la moral del pueblo ruso en la denominada "guerra patria rusa".

El gobierno soviético dejó en libertad a millares de obispos que se encontraban recluidos en los gulags de Siberia. Una iglesia ortodoxa, completamente supeditada al poder soviético, comenzó a abrir sus templos y proporcionó ayuda no sólo espiritual sino material para la compra de uniformes y aditamentos contra el frío. ${ }^{10}$ Este acercamiento fue descrito como una unión patriótica que tuvo su clímax en el recibimiento de varios metropolitanos y obispos por parte de Stalin en 1943.

Con el triunfo soviético en 1945, la Iglesia ortodoxa se vio favorecida por su apoyo a la causa contra los nazis, pero la reconciliación con el Estado sufrió un nuevo revés con la muerte de Stalin en 1953, miles de iglesias abiertas en la Unión Soviética fueron cerradas por cuestiones ideológicas y ello no cambió mucho, sino hasta el ascenso en 1985 de Mikhail Gorbachov como jefe del Partido Comunista de la URSS.
En su política de perestroika (restructuración) y glasnot (apertura), Gorbachov concedió libertades políticas y religiosas a los ciudadanos soviéticos. Así, los clérigos o líderes de las diversas religiones practicadas en territorio soviético tuvieron libertad para practicar sus actividades religiosas y desarrollaron la fuerza suficiente como para desatar una influencia política tal que alimentó la explosión de las problemáticas nacionalistas reprimidas durante el totalitarismo, colaborando con su granito de arena en la posterior desintegración de la Unión Soviética a finales de 1991.

\section{La Iglesia ortodoxa de la Rusia post soviética}

Boris Yeltsin, el entonces presidente de la federación rusa, tuvo un papel fundamental en la desintegración del Estado soviético. A su vez, la Iglesia ortodoxa retomó su lugar en el seno de la historia rusa, aunque se encontró de frente con la expansión de sectas religiosas con carácter místico y con la expresión dura del islam, esencialmente en el Cáucaso ruso y en los territorios de Asia central, donde habitan varios millones de rusos y ucranianos.

En el exterior, las guerras yugoslavas (1991-1995) también propiciaron un caldo de cultivo para el reforzamiento ideológico de la Iglesia ortodoxa rusa. Esto debido a la expresión desatada por los nacionalistas, oficiales del ejército, parlamentarios y algunos líderes rusos de la Iglesia ortodoxa que pedían a gri- 
tos el apoyo para los serbios, en una muestra de hermandad entre eslavos-ortodoxos en su lucha contra otros eslavos, musulmanes (bosnios) o católicos (croatas).

En septiembre 1997, Boris Yeltsin firmó una ley sobre la "libertad religiosa" respaldada por la Iglesia ortodoxa. Sin embargo, esta ley fue calificada por el Vaticano (y por algunos grupos de derechos humanos) como discriminatoria porque limita los derechos de los practicantes de las doctrinas religiosas no tradicionales de Rusia. Por su parte, el gobierno y algunos parlamentarios rusos argumentaron la importancia de esta ley para proteger a los ciudadanos rusos de inmiscuirse en lo que denominaron "sectas religiosas peligrosas que explotan la pobreza y la ignorancia de la población" (El Financiero, 29 de septiembre de 1997).

En su relación con el Vaticano, la Iglesia ortodoxa rusa no ha progresado mucho. Sus diferencias no sólo se basan en la liturgia, sino que aún hay cierto distanciamiento basado, en primera instancia, en la desconfianza que despierta entre los ortodoxos la creciente popularidad y poder de la figura del Papa Juan Pablo II, y temen que un acercamiento con la Santa Sede esté dirigido a una posterior unidad y a la consiguiente pérdida de su independencia religiosa (una cuestión inadmisible que tiene que ver de forma directa con el mismo sentimiento identitario y "único" de los ru$\operatorname{sos}) .{ }^{11}$

En segundo lugar, Moscú no perdona a Roma los agravios históricos como el saqueo de Constantinopla por parte de los cruzados en 1204, el apoyo prestado por la Iglesia católica a la invasión alemana y sueca en 1240 a Novgorod, y la toma de la capital rusa por los polacos católicos en 1610 .

Durante los últimos años de la era soviética, Mikhail Gorbachov visitó a Juan Pablo II en el Vaticano. Tras la caída de la Unión Soviética, los presidentes Boris Yeltsin y Vladimir Putin también han visitado la Santa Sede e invitado al pontífice a visitar Rusia.
En su pontificado, Juan Pablo II ha estado en más de 130 países, incluso ha llegado a visitar Azerbaidjan y Ucrania, donde existen numerosos católicos uniatos (de liturgia ortodoxa, pero que reconocen la autoridad del Papa como representante de Dios en la tierra). No obstante, jamás ha pisado Rusia, a pesar de haber sido invitado en repetidas ocasiones por los mandatarios ya mencionados. Ello debido a que el Papa no ha recibido la anuencia del patriarca Alexei II. ${ }^{12}$ Lo anterior muestra de forma clara el gran celo de poder que la Iglesia ortodoxa rusa guarda en su país y con los rusos más allá de sus fronteras.

\section{Conclusión}

Junto a su historia, lengua y alfabeto, la Iglesia ortodoxa forma parte importante de la personalidad del pueblo ruso. Pero es necesario mencionar que ha sido una celosa encubridora de las políticas más ineficaces e injustas de los zares y de sus camarillas a lo largo de la historia rusa, y en muchas ocasiones coparticipes del paraíso de impunidad y protección que disfrutaban los terratenientes en detrimento de millones de campesinos.

En los primeros años de la era soviética la Iglesia ortodoxa fue reprimida y relegada, y posteriormente Joseph Stalin la utilizó como un estratégico agente moral supeditado a sus designios. Tras la desaparición del Estado soviético la Iglesia ortodoxa está volviendo a tener un papel autónomo de gran importancia en la conciencia del ciudadano ruso y, en cierta medida, ha comenzado a ser favorecida por las administraciones de Yeltsin y Putin.

A su vez, la Iglesia ortodoxa ha tratado de salvar parte de su papel social en la historia de la Rusia zarista, lamentando los años del ateísmo oficial soviético, comenzado por beatificar a Nicolás II (18 de julio de 2000), argumentando su papel de mártir a manos de los bolcheviques.

Grosso modo, la Iglesia ortodoxa rusa es un importante ente de reconocimiento común entre los rusos, que ha aportado valores, creen- 
cias, instituciones y estructuras sociales e influencias políticas en la construcción no sólo de la identidad rusa en su historia, sino que también ha incidido de alguna forma en la propia estructura del Estado.

\section{Bibliografía}

Arreola Woog, Enrique (1994) Sobre rusos y Rusia: antología documental. México: Archivo General de la Nación.

Arrollo Pichardo, Graciela (1996) "Construcción y disolución del socialismo en la URSS y Europa del Este: una perspectiva teórico histórica”, en Coordinación de Relaciones Internacionales, núm. 69, enero-marzo. México: Facultad de Ciencias Políticas y Sociales de la UNAM.

Bazant, Jan (1991) Breve historia politico-social de Europa central y oriental de 1938 a 1993. México: Editorial Porrúa.

Blackburn Robert (1994) Después de la caída: el fracaso del comunismo y el futuro del socialismo. Editorial Cambio XXI México DF.

Bosch y Gimpera (1960) Problema indoeuropeo. Apéndice de Swdesh. Dirección General de Publicaciones. UNAM. México DF.

Duche, Jan (1966) Historia de la Humanidad. IV Tomo. Madrid-París: Ediciones Guadarrama.

Grimberg, Carl (1983) El siglo de Luis XIV. Tomo 8. México: Ediciones DAIMON. Manuel Tamayo.

Halliday, Fred (1994) Los finales de la Guerra Fría. En Blackburn Robert, Después de la caída: el fracaso del comunismo y el futuro del socialismo. Editorial Cambio XXI México DF.

Huntington, Samuel (1993) El choque de civilizaciones y la reconfiguración del orden mundial. Barcelona, España: Editorial Paidós Iberia S.A.

Krotkov, Boris (1984) “Años de duras pruebas”. Páginas de la historia rusa. Selecciones de la prensa soviética. Moscú.

Maier, Franz Georg (1974) Bizancio. Editorial Siglo XXI. México.

Mendoza Limón ,Dalia (1994) "La religión como elemento constitutuvo de la identidad de los pueblos; el caso de Rusia" en Coordinación de Relaciones Internacionales, núm. 51. México: Facultad de Ciencias Políticas y Sociales de la UNAM.

Onckin, George (1918) Historia universal. Barcelona, España: Montaner y Simón Editores.
Palmer y Colton (1980) Historia contemporánea. España: Editorial Akal.

Pascal, Hugo (1993) "Los primeros rusos: la Rus de Kiev" en Grandeza de la Historia, núm. 33, México: Grupo editorial AGA S.A.

Rauschenbach, Boris (1988) ¿Para qué Vladimiro cristianizó Rusia? Moscú: Selecciones de la Prensa Soviética.

Romañach Mousset, Pedro (1979) "Bulgaria: el estado más antiguo de Europa va a celebrar su 1300 aniversario" en Geomundo, núm. 10, México.

Villar, Francisco (1991) Los indoeuropeos y los orígenes de Europa: lenguaje e historia. España: Editorial Gredos.

Vujacic V. y V. Zaslavsky (1992) "La desintegración de la URSS y Yugoslavia y sus causas” en Debats, núm. 142, España.

Wigzell, Faith (1994) "Mitología de Europa central y oriental”, en World Mitology, Duncan Baird Publishers. Editorial Debate. Madrid.

\section{Fuentes hemerográficas}

\section{El Financiero.}

Russian Today.

\section{O tras fuentes}

Ministerio de Asuntos Exteriores de la Federación Rusa. Departamento de Información y Prensa de la Federación Rusa.

\section{Notas}

1 Fuente: Mitología de Europa central y oriental, Faith Wigzell. Publicado dentro de «World Mitology» Duncan Baird Publishers 1993. Traducción Flora Casas. Editorial Debate, 1994.

2 Cuando Vladimiro se hizo bautizar, el cristianismo ya se había extendido en algunas aldeas de Rusia; incluso, hacía tiempo que su abuela Olga se había hecho bautizar (Maier, 1983: 119)

3 Con el afán de asegurar la unión de sus tribus, Vladimiro se estableció en Kiev y buscó, en primera instancia, otorgar igualdad de derechos a todas las deidades de las diversas tribus rusas. Sin embargo, consciente de que las creencias paganas impedían en cierta medida acceder a relaciones internas más estables y de que su país se encontraba terriblemente atrasado en cuanto a la tecnología, Vladimiro optó por convertirse al cristianismo en la versión bizantina, la cual tenía el enorme tino de ser predicada al idioma vulgar o materno de diferentes pueblos de la región (Rauschenbach, 1988: 210).

4 Durante la Edad Media se practicaba la teoría de los tres lenguajes, la cual determinaba que para fines cul- 
turales y religiosos solo era lícito utilizar el hebreo, el griego y el latín; es decir, los tres idiomas en que aparecía la inscripción que Poncio Pilatos hizo colocar en la cruz donde murió Cristo (Romañach, 1979: 518). Dicha teoría era sostenida por los pragmáticos de Roma y sólo lograba alejar a las masas del adoctrinamiento debido a que la plebe no dominaba ninguno de esos idiomas. Por su parte, Bizancio promovió el adoctrinamiento de los pueblos utilizando el idioma materno de cada uno de ellos.

5 Ello también contribuyó, por su naturaleza, a una fragmentación e independencia jurisdiccional de aquellos patriarcados pertenecientes a los diferentes pueblos cristianizados e influenciados por Bizancio, convirtiéndose éstos en iglesias autónomas y autocéfalas, es decir, en iglesias puramente nacionales; no obstante, siguieron conservando una unidad doctrinal y de culto.

6 Alexander Nevsky sabía muy bien que era en vano cualquier resistencia contra los mongoles. En 1242 viajó a Sarai, en el Volga, y rogó a Batu Khan que no atacara Novgorod. El mongol accedió a la petición de Alejandro y éste siguió siendo príncipe de Novgorod, con el debido tributo a los mongoles. Pero los rusos de Novgorod no se sometieron fácilmente al compromiso de Nevsky y expulsaron a los emisarios de Batu Khan. En un nuevo intento por contener la ira del guerrero mongol, Nevsky hizo en 1263 otro viaje a Sarai para interceder por su pueblo. Consiguió que se suspendiera temporalmente el castigo, pero en el camino de regreso murió. La suerte de Rusia quedó dictada.

7 Sofía es una palabra de origen griego que tuvo un papel fundamental en el cristianismo temprano. Formaba parte de la tríada como Espíritu Santo. Sofía significa seno materno y alegría, la sabiduría divina plasmada en el "YO de Dios". A su vez, en la tradición bizantina, el cristianismo era descrito como la llegada de la sabiduría divina. En ese sentido, Rusia había sido bendecida por la llegada de Sofía (Mendoza Limón, 1996: 81).

8 En 1610 los polacos, poderosos en aquellos tiempos, invadieron el oeste de Rusia y tomaron a sangre y fuego la ciudad de Moscú, un acto que hasta la fecha es duro de dirimir para los rusos. En esos momentos difíciles, la Iglesia ortodoxa volvió a tener un papel fundamental en el patriotismo ruso que permitió hacer frente a los invasores y que a la postre facilitó el desalojo de los invasores.

9 El paneslavismo fue un movimiento desarrollado durante el siglo XIX, dirigido desde Rusia, que aspiraba a la expansión territorial. Con esta tendencia, Rusia pretendía liberar a todos los pueblos eslavos ortodoxos y colocarlos bajo su protección. A finales del siglo XIX el paneslavismo se fue convirtiendo en una corriente que se denominó eslavofilia, la cual otorgaba a Rusia la misión de influenciar también a los eslavos no ortodoxos como croatas, polacos y checos, y regenerarlos con su religión ortodoxa (Bazant, 1991, 147).

10 Una de las contribuciones materiales más destacadas de la Iglesia ortodoxa en la lucha contra los alemanes fue el financiamiento del tanque San Dimitry Donskoy y del escuadrón de Alexander Nevsky.

11 El autor ruso Dimitry Merejkovsky describe la religiosidad rusa en su poema histórico El Anticristo. Uno de los personajes, Alexis, el hijo de Pedro I, conversa con una dama de honor de su esposa, una alemana a la que le exclama lo siguiente: “¿Crees verdaderamente en Cristo? Ah, vosotros los occidentales, sois inteligentes, fuertes, justos, sois respetados y lo sabeis todo; pero no poseéis a Cristo. ¿Y qué harías de él? Os redimís a vosotros mismos. En cuanto a nosotros, somos como unas bestias, vivimos desnudos, borrachos, sucios, peores que bárbaros y que los mismos animales; en cambio nuestro padrecito Jesucristo está con nosotros y permanecerá con los rusos por toda la eternidad, él es el Santo que nos redimirá" (Grimber, 1983: 306-307).

12 El Papa sólo visita un país no católico cuando recibe la anuencia del líder de la mayoría religiosa local. Así, ha recorrido casi todas las naciones de Europa oriental y el Cáucaso, donde se practica la cristiandad ortodoxa. En el caso de Rusia, el patriarca de Moscú, Alexei II, se ha negado a recibirlo. 